\title{
POTENTIAL USE OF SOME PSEUDOCEREALS IN THE FOOD INDUSTRY
}

\author{
Viktorija Stamatovska ${ }^{1}$, Gjore Nakov ${ }^{2}$, Zora Uzunoska ${ }^{1}$, Tatjana Kalevska ${ }^{1}$ \& Marija \\ Menkinoska $^{1}$ \\ ${ }^{1}$ Faculty of Technology and Technical Sciences, University St. Kliment Ohridski of Bitola, \\ Dimitar Vlahov bb, 1400 Veles, Republic of Macedonia \\ e-mail: vikistam2@gmail.com \\ 'Department of Biotechnology and Food Technologies, University of Ruse "Angel Kanchev", \\ Branch Razgrad, Aprilsko vastanie Blvd. 47, 7200 Razgrad, Bulgaria \\ e-mail: gore_nakov@hotmail.com
}

\begin{abstract}
Pseudocereals and cereals are plant materials that have similar final uses as flours for bakery products. However, these plants are different botanically, as pseudocereals they are broadleaf plants, whereas as cereals they are grasses. The use of pseudocereals is of great nutritional interest because of their composition. Besides the high starch content, pseudocereals contain dietary fibre, good quality protein, vitamins, minerals, lipids rich in unsaturated fatty acids and other phytochemicals such as saponins, phytosterols, squalene, fagopyritols and polyphenols. This composition describes their potential as supplements or common cereal replacers. Because their content of gluten is low or there is no content of gluten, pseudocereals can be considered as gluten-free products, which can be incorporated in diets for coeliac disease. The incorporation of these seeds in the diets of coeliac patients should help alleviate the deficit in fibre intake. Their applicability in foods includes bread, biscuits, cakes and pasta which are mostly consumed. The three main species referring to pseudocereals are amaranth, quinoa and buckwheat. The aim of this study is to provide their applications in food products.
\end{abstract}

Keywords: pseudocereals, use, food industry.

\section{INTRODUCTION}

The opportunity to supplement or completely replace common cereal grains (corn, rice or wheat) with a higher nutritional value cereal is becoming increasingly popular among people interested in improving and maintaining their health status by changing dietary habits [42]. Currently there is much bigger interest in the use of pseudocereals for developing nutritious food products. Amaranth (Amaranthus spp.), buckwheat (Fagopyrum spp.), and quinoa (Chenopodium spp.) are the three major pseudocereals in terms of world production [22]. Generally, two Fagopyrum species are produced all over the world, common buckwheat (Fagopyrum esculentum Möench L.) and tartary buckwheat (Fagopyrum tataricum Gärtn L.). Common buckwheat, the most widely consumed variety, has sweeter taste, larger seeds and is easier to dehull than tartary buckwheat [24].

Pseudocereal grains such as buckwheat, amaranth and quinoa are rich in a wide range of compounds e.g. starch, proteins, dietary fiber, flavonoids, phenolic acids, trace elements, fatty acids, vitamins, and other bioactive substances with known effects on human health [24, $19,4,43,40,30,7,13,2,21,25,6]$. The attributed health benefits have been associated with reduced risk of some diseases such as celiac, high blood pressure, diabetes, cardiovascular disease and cancer $[3,31,9,13,44,18]$. Based on high contents of polyphenols, anthocyanins, flavonoids and their antioxidant activities pseudocereals such as 


\section{ARTTIE $Y$}

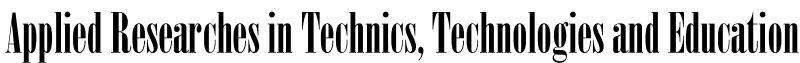

Journal of the Faculty of Technics and Technologies, Trakia University https://sites.google.com/a/trakia-uni.bg/artte/

buckwheat, quinoa and amaranth can be a substitute for cereals for common and atherosclerotic diets and sometimes in the cases of allergy [19].

Amaranth, quinoa and buckwheat are not true cereals, they are dicotyledonous plants as opposed to most cereals (e.g. wheat, rice, barley) which are monocotyledonous, but they produce seeds that can be milled into flour and used as a cereal crop [22, 3]. Their variable applicability in foods includes items like bread, biscuits, cakes and pasta which are the most consumed and therefore appropriate carriers for protein enrichment [42].

In recent years, there has been an increasing interest on gluten-free foodstuffs [17]. Results from a number of recent studies have highlighted the need for an improvement in the nutritional quality of cereal based gluten-free products [3]. use of gluten-free products is increasing since a growing number of people are suffering from celiac disease and they need gluten-free diet. Many gluten-free products have been put into production including glutenfree bread, pasta, noodles, cookies and other snacks [27, 16]. The pseudocereals amaranth, quinoa and buckwheat are also gluten-free grains. Because of their low or no content of gluten, the main protein present in most common cereals, these pseudocereals can be considered as gluten-free products and be suitable for incorporation into the diet for celiac disease patients [42]. This article reviews the application of pseudocereals such as buckwheat, amaranth and quinoa in the production of food products.

\section{USE IN THE FOOD INDUSTRY}

A growing number of studies have investigated the application of pseudocereals in the production of food products such as bread, pasta, noodles, biscuits and other confectionary products.

Wheat bread is the main diet in most countries all over the world. It is an excellent source of minerals, especially phosphorus and copper, numerous vitamins, and carbohydrates. However, white bread is considered to be nutritionally poor, as the wheat proteins are deficient in essential amino acids such as lysine, tryptophan, and threonine. Various sources of pseudo-cereal flour are used in bread making include amaranth, buckwheat, and quinoa. These ingredients which are good sources of proteins, carbohydrates, dietary fibers, minerals and are also rich in lysine, leucine and arginine can fulfil the amino acids requirement and provide beneficial physiological effects to consumers [1].

Pseudocereals have been incorporated in bread formulations in order to improve its nutritional profile. Chlopicka et al. [11] analysed the effect of adding $15 \%$ and $30 \%$ of pseudocereal flours (buckwheat, amaranth and quinoa), on the antioxidant capacity and sensory value of breads. The $30 \%$ dose was more effective in enhancing antioxidant activity than the $15 \%$ dose. The addition of buckwheat flour to wheat flour improved more effectively the antioxidant status of bread than other studied pseudocereals, amaranth and quinoa. Buckwheat bread had the highest content of phenolic compounds. Analysis of sensory quality results of bread showed that addition of pseudocereals flour (especially buckwheat and quinoa flour) to wheat flour may increase acceptable quality attributes such as taste, colour and smell. The best opinion about the colour and smell was about the buckwheat bread. The results indicate that bread fortified with pseudocereal flours, particularly with buckwheat flour, but depending on the dose, may improve not only antioxidant but also sensory properties of bread and this bread may be chosen by consumers as preferred.

Buckwheat polyphenols are represented by phenolic acids and flavonoids, mainly routine, a proven potent antioxidant. As the largest amount is contained in the hull and the outer layers of the grain, the wholegrain buckwheat flour is richer in polyphenols than the light buckwheat flour. Therefore, the wholegrain buckwheat flour is characterized by a higher antioxidant capacity. Due to a relatively high content of antioxidants, wholegrain buckwheat flour is used for substitution of wheat or other cereal flour in bakery, pasta and confectionary formulations

IRTIIE Vol. 6, No. 1, 2018 ISSN 1314-8788 (print), ISSN 1314-8796 (online), doi: 10.15547/artte.2018.01.009 


\section{ARTTIE $Y$}

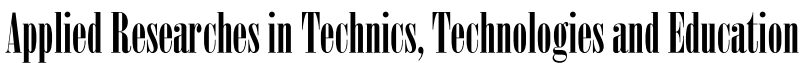

Journal of the Faculty of Technics and Technologies, Trakia University https://sites.google.com/a/trakia-uni.bg/artte/

in order to create either added value or gluten-free products. The aim of a long-term consumption of buckwheat flours is to achieve health benefits and to protect from many chronic diseases [31].

Bojňanská et al. [8] showed that the consumption of bread enriched by an addition of $30 \%$ buckwheat (an amount acceptable from the technological point of view based on arheological tests and a baking experiment) as well as from the sensory point of view containing antioxidant flavonoid compounds (mainly rutin), can have a positive increase on the serum antioxidant capacity in humans. The research also showed that the addition of buckwheat increased the content of proteins, minerals, and fibers. In the other study, it has been reported that the use of whole buckwheat flour (WBF) in the elaboration of Turkish flat bread, lavaş, increased the content of fiber, phytic acid, and mineral ( $\mathrm{Fe}, \mathrm{K}, \mathrm{Mg}$ and $\mathrm{P}$ ). WBF provided darker crust of the bread as a result of natural pigmentation. WBF up to $30-40 \%$ proportion with gluten and sodium stearoyl-2-lactylate (SSL) can be used in the lavaş bread formula to enrich the bread, taking the optimum physical and sensorial properties of bread into consideration [46].

Buckwheat flour applied as a component of gluten-free formulas improves the nutritional value and technological parameters of gluten-free bread. It affects positively the technological quality of bread, like the specific volume index of bread and the size of the loaf. Buckwheat flour enriched gluten-free bread with proteins and microelements, especially with copper and manganese, but also with iron and zinc. Therefore, the utilisation of buckwheat flour both as a valuable nutrient and a factor improving technological properties of gluten-free bread can be highly recommended [23]. Five types of bread, made of corn flour (100\%), rice flour (100\%), corn and rice flour (50:50\%), buckwheat, corn, and rice flour (30:35:35\%), were analyzed by Różyło et al. [32] It has been noticed that, by changing the amount of water addition to the dough, it is possible to significantly affect the quality of different types of natural gluten-free bread. Addition of water from 80 to $120 \%$ of flour mass, resulted in significant changes in the quality of bread. Bread made of corn flour required the largest amount of water addition (120\%); however, bread made of rice flour was characterized by a better quality with the lowest amount of water addition (80\%), while bread made of corn and rice flour and buckwheat, corn, and rice flour was characterized by the best quality when the amount of water addition was $90 \%$. In a more recent study Piasecka-Jóźwiak et al. [29], organic wholegrain buckwheat flour or mixtures of this flour with rice and maize flour (each on substitution level $20 \%$ ) have been used in formulations for gluten-free bread. The bread was made with the use of buckwheat sourdough obtained with starter culture composed of autochthonous lactic acid bacteria strains. The obtained breads were characterized in terms of quality and biologically active phenolic compounds content and antioxidant activity (AOA). The results demonstrated that organic buckwheat flour could be used as a sole raw material for baking GF bread, acceptable in terms of taste and flavor and characterized by high amounts of phenolic compounds (387 mg GAE/100g) and antioxidant activity.

The application of amaranth and quinoa in gluten-free products has also been studied. Alvarez-Jubete et al. [4] studied the application of amaranth, buckwheat and quinoa seeds in the production of gluten-free bread. The pseudocereal containing gluten-free bread showed significantly higher levels of protein, fat, fibre and minerals than the control bread. Amaranth, buckwheat and maize flours were used by Ziobro et al. [47] in formulations for gluten-free bread based on starch and hydrocolloids, replacing $10 \%$ of starch. The evaluation of physical parameters of the loaves proved that, at the applied level of addition, their quality was not deteriorated. In the case of buckwheat, some positive influence on texture during storage could be observed. The application of non-wheat flour caused a significant change in the content of nutritionally important constituents of bread. Bread with buckwheat flour contained the highest amount of polyphenols, including phenolic acids, flavonols, anthocyanins and flavonoids, which resulted in their highest antioxidant activity among all analysed bread

IRTIIE Vol. 6, No. 1, 2018 ISSN 1314-8788 (print), ISSN 1314-8796 (online), doi: 10.15547/artte.2018.01.009 


\section{ARTTIE $Y$}

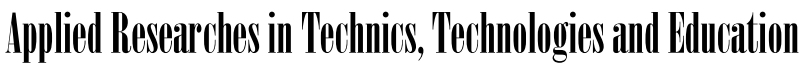

Journal of the Faculty of Technics and Technologies, Trakia University https://sites.google.com/a/trakia-uni.bg/artte/

samples. Taking into account all analysed gluten-free kinds of bread with the share of nonwheat flour, it could be observed that supplementation with buckwheat flour was the most effective regarding the increase of nutritional constituents and bioactive compounds with an antioxidant character. In other recent study, Shehry [34] substituted corn flour (at $25 \%, 50 \%$ and $75 \%$ ) with quinoa flour to produce gluten free bakery product such as pan bread or biscuits. The results showed that, protein, ash, fiber, fat and mineral elements levels are higher in the quinoa flour than the corn flour, causing rise in protein, ash, fiber and fat in the composite flour, thus improving the nutritional characteristics of the product. Generally, replacement levels $25 \%$ and $50 \%$ of quinoa flour showed acceptable results in the sensory and physical properties in both pan bread and biscuits with a significant improvement in the nutritional qualities.

Also, flour from amaranth, buckwheat and quinoa has been incorporated in pasta and noodle formulations. Alvarez-Jubete et al. [3], Valcárcel-Yamani \& Lannes [42], Giménez-Bastida et al.[16], Giménez-Bastida et al. [17] and Janssen et al. [22] present data that number of scientists have published giving a detailed overview of the application of amaranth, quinoa and buckwheat in the production of pasta and noodles. In recent study, new wholegrain tagliatelle formulations, with different wholegrain buckwheat flour content $(10 \%-30 \%)$ have been developed [38]. Sensory, nutritional and functional quality parameters of buckwheat containing tagliatelle samples were analysed and compared with control tagliatelle sample from wholegrain wheat flour. The obtained results indicate that wholegrain buckwheat flour (autoclaved or non-treated) inclusion into tagliatelle formulation led to an improvement of nutritional and functional profiles of tagliatelle samples, followed by greater or lesser deterioaration of sensory profile, depending on the substitution level and the type of wholegrain buckwheat flour.

One of the possible ways to promote the use of buckwheat could be its utilization in biscuits , cookies and crackers. Formulations of gluten-free cookies based on rice and buckwheat flour in three different ratios, 90/10, 80/20 and 70/30, were developed by Torbica et al. [41]. Measurements performed in this study revealed that mixtures of rice and buckwheat flour can be successfully included into gluten-free cereal-based products, resulting in cookies of pleasant flavour and acceptable technological quality expressed in shape, cross section structure, rupture, and appearance of top and bottom surfaces. Generally, observing all the evaluated attributes, cookie formulations prepared with $20 \%$ of buckwheat flour expressed the most acceptable sensory properties. Hadnađev et al. [20]) studied the influence of buckwheat flour and the hydrocolloid carboxymethyl cellulose (CMC) on the production of sheathable gluten-free cookies. The buckwheat flour was used to replace $10 \%, 20 \%$ and $30 \%$ of rice flour in gluten-free formulations. The results of the physical and sensory evaluation of gluten-free cookies showed that buckwheat addition led to a decrease in cookie hardness and fracturability and an increase in eccentricity (deformation from regular shape) as well as the overall acceptability. Chopra et al. [12] concluded that buckwheat flour can be successfully incorporated in wheat flour up to a level of $75 \%$ to yield cookies of enhanced nutritional quality with acceptable sensory attributes.

Buckwheat can be incorporated into ginger nut biscuit up to $50 \%$ as it provides a sensory acceptable product with enhanced nutritional and bio-functional properties [15]. Measurements performed by Öksüz \& Karakaş [26] revealed that including egg white, carob syrup and purified starches in biscuit recipes based on buckwheat flour yielded final products with significantly different nutritional, sensory and textural properties.

In a study carried out by Starowicz et al. [39], rye-buckwheat ginger cakes enriched with rutin were developed. Enrichment of rye-buckwheat ginger cakes with rutin improved their antioxidant properties, showed protective effect on lysine blockage resulting in lower furosine formation whereas stimulated the Maillard reaction (MR) progress to the melanoidin

IRTIIE Vol. 6, No. 1, 2018 ISSN 1314-8788 (print), ISSN 1314-8796 (online), doi: 10.15547/artte.2018.01.009 


\section{ARTTE $Y$ Y}

Ipplied Resseirlohes in Technics, Technologies and Bductation

Journal of the Faculty of Technics and Technologies, Trakia University https://sites.google.com/a/trakia-uni.bg/artte/

formation. In contrast, the loss of nutritional quality of rye-buckwheat ginger cakes enriched with rutin was noted due to formation of carboxymethyllysine and fluorescent compounds linked-toprotein at the advanced stage of MR. This study suggests that ryebuckwheat ginger cakes enriched with rutin may be recommended for wider nutrition.

Wójtowicz et al. [45] showed the influence of buckwheat addition on physical properties, texture, colour and sensory characteristics of extruded corn snacks. The best acceptability was concluded for corn snacks enriched with buckwheat at a level not exceeding $30 \%$, Higher dose of the additive gave specific buckwheat flavour to snacks.

Whole amaranth flour as a good source of protein seems to be suitable for the preparation of sugar snap cookies. Studies on composite amaranth-wheat flour cookies have indicated that incorporation of amaranth flour improved the quality of cookies even at $25 \%-30 \%$ replacement of wheat flour [37]. In recent study, gluten free cookies have been prepared from raw and germinated amaranth grain flour. Germinated amaranth cookies showed the highest antioxidant activity and total dietary fibre as compared to raw amaranth and wheat flour cookies [10]. Eggless cakes were prepared by using different levels of amaranth flour $(20 \%, 40 \%, 60 \%, 80 \%$ and $100 \%)$ into refined wheat flour with the constant level of whey protein concentrate $[35,36]$. The overall acceptability scores of $40 \%$ amaranth flour cakes were maximum and more than control for cakes.

Atef et al. [5] observed that quinoa meal can be blended with wheat flour at levels as high as $75 \%$ without adversely affecting baking performance of salt-biscuit and pancake, but meal sample with $100 \%$ of quinoa was acceptable with slight differences compared control in cake sample. Quinoa flour has been used to develop gluten - free cookies. Quinoa and rice flour can be combined to produce acceptable cookies with a greatly improved nutritional quality. Păucean et al. [28] showed that up to $45 \%$ quinoa flour could be incorporated into rice flour without adverse effect on the quality of the cookies. At this level of addition, the protein content increased almost three fold from $9.5 \%$ to $19.69 \%$.

\section{CONCLUSIONS}

The development of new functional foods and healthy products is one of the most attractive trends for the food industry. There is currently much bigger interest in the use of pseudocereals for developing nutritious food products. Amaranth, buckwheat, and quinoa are the three major pseudocereals in terms of world production. The well-balanced amino acid composition and the high levels of dietary fiber, antioxidants, vitamins, and minerals make pseudocereals interesting raw materials for highly nutritious cereal-based food systems. Pseudocereals can provide beneficial health effects therefore food with addition of buckwheat, amaranth or quinoa flour, as a staple product could diversify the daily model of nutrition.

The growing demand for high-quality and nutrient-dense gluten-free products has increased the incorporation of pseudocereals in wheat and gluten-free food formulations. Therefore, a number of gluten-free products containing pseudocereals have been developed, such as gluten-free bread, biscuits, pasta, crackers etc. Several studies have reported the successful formulation of pseudocereal-containing gluten-free cereal based products such as bread, pasta and confectionary products. However, the availability of these products on the market is still quite limited.

Although the quality of gluten-free cookies has been improved, additional research is necessary to fully exploit the functionality of these seeds as gluten-free ingredients in the production of palatable products which are also nutritionally balanced. 


\section{REFERENCES}

[1] Aghamirzaei M., Heydari-Dalfard A., Karami F. \& Fathi M. (2013). Pseudo-cereals as a functional ingredient: effects on bread nutritional and physiological properties - Review. Intl J Agri Crop Sci, Vol. 5 (14), (2013), pp. 1574-1580.

[2] Ahmed A., Khalid N., Ahmad A., Abbas A. N., Latif Z. S. M. \& Randhawa A. M. (2014). Phytochemicals and biofunctional properties of buckwheat: a review. Journal of Agricultural Science, Vol. 152, (2014), pp. 349-369.

[3] Alvarez-Jubete L., Arendt E. K. \& Gallagher E. (2010). Nutritive value of pseudocereals and their increasing use as functional gluten - free ingredients. Trends in Food Science \& Technology, Vol. 21, (2010), pp. 106-113.

[4] Alvarez-Jubete L., Arendt E. K. \& Gallagher E. (2009). Nutritive value and chemical composition of pseudocereals as gluten-free ingredients. International Journal of Food Sciences and Nutrition, Vol. 60 (S4), (2009), pp. 240-257.

[5] Atef A., Abou-Zaid M.A., El-Faham Wafaa Y. S. (2012). Use of Quinoa Meal to Produce Bakery Products to Celiac and Autism Stuffs. International Journal of Science and Research (IJSR), Vol. 3 (9), (2012), pp. 1344-1354.

[6] Bhat A., Satpathy G. \& Gupta K. R. (2015). Evaluation of Nutraceutical properties of Amaranthus hypochondriacus L. grains and formulation of value added cookies. Journal of Pharmacognosy and Phytochemistry, Vol. 3 (5), (2015), pp. 51-54.

[7] Biela W. \& Maciorowski R. (2013). Evaluation of chemical composition and nutritional quality of buckwheat groat, bran and hull (Fagopyrum Esculentum Möench L.). Ital J Food Sci, Vol. 25, (2013), pp. 384-389.

[8] Bojňanská T., Frančáková H., P. Chlebo P. \& Vollmannová A. (2009). Rutin Content in Buckwheat Enriched Bread and Influence of its Consumption on Plasma Total Antioxidant Status. Czech J Food Sci, Vol. 27, Special Issue, (2009), pp. S236-S241.

[9] Caselato-Sousa M. V. \& Amaya-Farfàn J. (2012). State of Knowledge on Amaranth Grain: A Comprehensive Review, Journal of Food Science, Vol. 77, No. 4, pp. R93R104.

[10] Chauhan A., Saxena D. \& Singh S. (2015). Total dietary fibre and antioxidant activity of gluten free cookies made from raw and germinated amaranth (Amaranthus spp.) flour. LWT - Food Science and Technology, Vol 63, Issue 2, (2015), pp. 939-945.

[11] Chlopicka J., Pasko P., Gorinstein S., Jedryas A. \& Zagrodzki P. (2012). Total phenolic and total flavonoid content, antioxidant activity and sensory evaluation of pseudocereal breads. LWT - Food Science and Technology, Vol 46, (2012), pp. 548-555.

[12] Chopra N., Dhillon B. \& Puri S. (2014). Formulation of Buckwheat Cookies and their Nutritional, Physical, Sensory and Microbiological Analysis. International Journal of Advanced Biotechnology and Research (IJBR), Vo I5, Issue 3, (2014), pp. 381-387.

[13] Dębski B.,Gralak A. M., Bertrandt J. \& Kłos A. (2013). Minerals and polyphenols content of quinoa (Chenopodium quinoa Willd.) plant. Probl Hig Epidemiol, Vol. 94 (2), (2013), pp. 300-304.

[14] Farinazzi-Machado V. M. F., Barbalho M.S., Oshiiwa M., Goulart R. \& Pessan Junior O. (2012). Use of cereal bars with quinoa (Chenopodium quinoa W.) to reduce risk factors related to cardiovascular diseases. Ciênc Tecnol Aliment, Campinas, Vol. 32 (2), (2012), pp. 239-244.

[15] Filipčev B., Šimurina O., Sakač M., Sedej I., Jovanov P., Pestorić M. \& Bodroža-Solarov M. (2011). Feasibility of use of buckwheat flour as an ingredient in ginger nut biscuit formulation. Food Chemistry, Vol. 125, (2011), pp. 164-170.

[16] Giménez-Bastida J.A., Piskuła K. M. \& Zieliński H. (2015). Recent Advances in Processing and Development of Buckwheat Derived Bakery and Non-Bakery Products a Review. Pol J Food Nutr Sci, Vol. 65, No. 1, (2015), pp. 9-20.

IRTIIE Vol. 6, No. 1, 2018 ISSN 1314-8788 (print), ISSN 1314-8796 (online), doi: 10.15547/artte.2018.01.009 
[17] Giménez-Bastida J. A., Piskuła M. \& Zieliński H. (2015). Recent advances in development of gluten-free buckwheat products, Trends in Food Science \& Technology, Vol. 44, Issue 1, (2015), pp. 58-65.

[18] Gordillo-Bastidas E., Díaz-Rizzolo D.A., Roura E., Massanés T. \& Gomis R. (2016). Quinoa (Chenopodium quinoa Willd), from Nutritional Value to Potential Health Benefits: An Integrative Review. J Nutr Food Sci, Vol. 6, Issue 3, (2016), p. 497.

[19] Gorinstein S., Vargas M.J.O., Jaramillo O. N., Salas A. I. Ayala M. L. A., Arancibia-Avila P., Toledo F., Katrich E. \& Trakhtenberg S. (2007). The total polyphenols and the antioxidant potentials of some selected cereals and pseudocereals. Eur Food Res Technol, Vol. 225, (2007), pp. 321-328.

[20] Hadnađev D. R. T., Torbica M. A. \&. Hadnađev S. M. (2013). Influence of Buckwheat Flour and Carboxymethyl Cellulose on Rheological Behaviour and Baking Performance of Gluten-Free Cookie Dough. Food Bioprocess Technol, 6, (2013), pp. 1770-1781.

[21] Hofmanová T., Švec I. \& Hrušková M. (2014). Nutritional Properties of Non-Traditional Seeds. JLM, Vol. 2, Issue 1, (2014), pp. 10-14.

[22] Janssen F., Pauly A., Rombouts I., Jansens A.J. K., Deleu J. L. \& Delcour A. J. (2017). Proteins of Amaranth (Amaranthus spp.), Buckwheat (Fagopyrum spp.), and Quinoa (Chenopodium spp.). A Food Science and Technology Perspective. Comprehensive Reviews in Food Science and Food Safety, Vol 16, Issue 1, (2017), pp. 39-58.

[23] Krupa-Kozak U., Wronkowska M. \& Soral-Śmietana M., (2011). Effect of buckwheat flour on microelements and proteins contents in gluten-free bread. Czech J Food Sci, Vol. 29, (2011), pp. 103-108.

[24] Léder I., Adányi N., Daood G. H., Sass-Kiss Á. \& Kardos-Neumann Á. (2010). Study of the Composition and Radical Scavenging Capacity of Buckwheat Seed and Buckwheat Leaf Flour of Two Cultivars Grown in Hungary. The European Journal of Plant Science and Biotechnology, Vol. 4, (Special Issue 1), (2010), pp. 87-92.

[25] Ogrodowska D., Zadernowski R., Czaplicki S., Derewiaka D. \& Wronowska B. (2014). Amaranth Seeds and Products - The Source of Bioactive Compounds. Pol J Food Nutr Sci, Vol. 64, No. 3, (2014), pp. 165-170.

[26] Öksüz T. \& Karakaş B., (2016). Sensory and textural evaluation of gluten-free biscuits containing buckwheat flour. Cogent Food \& Agriculture, 2:1178693, (2016), pp.1-7.

[27] Padalino L., Conte A. \& Del Nobile A. M. (2016). Overview on the General Approaches to Improve Gluten-Free Pasta and Bread. Foods, Vol. 5 (4), (2016), p. 87.

[28] Păucean A., Man S., Muste S. \& Pop A. (2015). Effect of quinoa flour addition on quality characteristics of rice gluten-free cookies. Journal of Agroalimentary Processes and Technologies, Vol. 21 (4), (2015), pp. 371-378.

[29] Piasecka-Jóźwiak K., Słowik E., Rozmierska J. \& Chabłowska B. (2016). Development of organic buckwheat gluten-free bread, characterized by a high level of bioactive compounds. Journal of Research and Applications in Agricultural Engineering, Vol. 61 (4), (2016), pp. 110-116.

[30] Repo-Carrasco-Valencia A.-M. R. \& Serna A. L. (2011). Quinoa (Chenopodium quinoa, Willd.) as a source of dietary fiber and other functional components. Ciênc Tecnol Aliment, Campinas, Vol. 31 (1), (2011), pp. 225-230.

[31] Rokka S., Järvenpää E. \& Tahvonen R., (2010). Glycemic index of buckwheat bread. NJF Report, Vol.6, No 2, (2010), pp. 77-79.

[32] Różyło R., Dziki D., Gawlik-Dziki U., Cacak-Pietrzak G., Miś A. \& Rudy S. (2015). Physical properties of gluten-free bread caused by water addition. Int Agrophys, Vol. 29, (2015), pp. 353-364.

[33] Sakač B. M., Sedej J. I., Mandić I. A. \& Mišan Č. A. (2015). Antioxidant properties of buckwheat flours and their contribution to functionality of bakery, pasta and confectionary products. Hem ind, Vol. 69 (5), (2015), pp. 469-483.

IRTIIE Vol. 6, No. 1, 2018 ISSN 1314-8788 (print), ISSN 1314-8796 (online), doi: 10.15547/artte.2018.01.009 


\section{ARTTIE $Y$}

Ipplied Resseirlohes in Technics, Technologies and Bductation

Journal of the Faculty of Technics and Technologies, Trakia University https://sites.google.com/a/trakia-uni.bg/artte/

[34] Shehry A. A. G. (2016). Use of Corn and Quinoa Flour to Produce Bakery Products for Celiac disease. Advances in Environmental Biology, Vol. 10 (12), (2016), pp. 237-244.

[35] Shinde S. R. \& Raghuvansh S. R. (2013). Standardization of Cakes by using Different Levels of Amaranth Flour and its Acceptability. International Journal of Science and Research (IJSR), Volume 4, Issue 6, (2013), pp. 1859-1861.

[36] Shinde S. R. \& Raghuvansh S. R. (2015). Studies on standardization and physicochemical properties of Amaranth flour cakes. Asian J Home Sci, Vol. 10 (2), (2015), pp. 285-289.

[37] Sindhuja A., Sudha L. M. \& Rahim A. (2005). Effect of incorporation of amaranth flour on the quality of cookies. Eur Food Res Technol, Vol. 221, (2005), pp. 597-601.

[38] Škrobot D. (2016). Sensory, nutritional and functional profile of whole grain pasta with buckwheat flour addition. PhD Thesis. University of Novi Sad, Faculty of Technology, (2016).

[39] Starowicz M., Ciesarová Z. \& Henryk Zieliński H. (2017). Analysis of the antioxidative properties and Maillard reaction products in ginger cakes enriched with rutin. Madridge $\mathrm{J}$ Food Tech, Vol. 2 (1), (2017), pp. 44-52.

[40] Toader M., Roman V. GH. \& Ionescu A.-M. (2011). Chemical composition and nutritional values of some alternative crops promoted in organic agriculture. UASVM Bucharest, Series A, Vol. LIV, (2011), pp. 293-296.

[41] Torbica A., Hadnađev M. \& Hadnađev D. T. (2012). Rice and buckwheat flour characterisation and its relation to cookie quality. Food Research International. Vol. 48, (2012), pp. 277-283.

[42] Valcárcel-Yamani B. \& Lannes da S. C. S. (2012). Applications of Quinoa (Chenopodium Quinoa Willd.) and Amaranth (Amaranthus Spp.) and Their Influence in the Nutritional Value of Cereal Based Foods. Food and Public Health, Vol. 2 (6), (2012), pp. 265-275.

[43] Vega-Galvez A., Miranda M., Vergara J., Uribe E., Puente L. \& Martinez E. A. (2010). Nutrition facts and functional potential of quinoa (Chenopodium quinoa Willd.), an ancient Andean grain: a review, J Sci Food Agric, Vol. 90, (2010), pp. 2541-2547.

[44] Vélez-Jiménez E., Tenbergen K., Santiago P. D. \& Cardador-Martínez M. A. (2014). Functional Attributes of Amaranth, Austin J Nutri Food Sci, Volume 2, Issue 1, (2014), pp.1-6.

[45] Wójtowicz A., Kolasa A. \& Mościcki L. (2013). Influence of Buckwheat Addition on Physical Properties, Texture and Sensory Characteristics of Extruded Corn Snacks. Pol J Food Nutr Sci, Vol. 63, No. 1, (2013), pp. 239-244.

[46] Yıldız G. \& Bilgiçli N. (2012). Effects of whole buckwheat flour on physical, chemical, and sensory properties of flat bread, Lavaş. Czech J Food Sci, Vol. 30, (2012), pp. 53-540.

[47] Ziobro R., Gumul D., Korus J. \& Korus A. (2016). Starch bread with a share of nonwheat flours as a source of bioactive compounds in gluten-free diet. Journal of Food and Nutrition Research, Vol. 55, No. 1, (2016), pp. 11-21. 